\title{
Study on Influence of the Number of Assembly \& Disassembly of Special Screws in Glued Laminated Bamboo Wood on the Joint Strength
}

\author{
Hengwang Zhang \\ Shandong University of Arts \\ Shandong, China \\ Email: 403676956@qq.com
}

\begin{abstract}
Screw joint is one of the basic joint forms applied in glued laminated bamboo wood. This paper is based on the basic elements of the special thread of glued laminated timber, and through test to discuss the influence of assembly \& disassembly number factor of screw joint on the mechanical properties of screw joint, and the following conclusions are drawn: the joint strength decreases with the increase of the number of assembly \& disassembly, and the two have a negative linear correlation, which can be expressed by $\mathbf{y}=$ $-65.76 x+9550.10$, the correlation coefficient is $R=-0.98$ and the correlation is very close. The conclusion of this paper can provide reference for solving the problems in actual production.
\end{abstract}

Keywords: Glued Laminated Bamboo Wood; Screws; Number of Assembly \& Disassembly; Joint Strength

\section{INTRODUCTION}

Facing the situation of tight supply of wood materials, glued laminated bamboo wood has gradually become a widely used wood material. It is a new type of furniture base material and keeps the bamboo characteristics of good physical and mechanical properties and low shrinkage, its bending strength, compressive strength and tensile strength are all large, and the expansion, shrinkage and deformation are relatively small, so it can be comparable to high-quality hardwood. These excellent characteristics of glued laminated bamboo wood have alleviated the severe raw material supply situation in China, and the broad application prospects have brought about the research and development of related ancillary products.

In terms of microstructure and macro characteristics, there is a big difference among glued laminated bamboo wood, wood and wood-based panel, and in the process of manufacturing, the technology is also different from other materials. Due to the special properties of bamboo, the screws used in the common wood materials will have the problems such as weak connection, difficulty in screwing and breaking of screws when they are connected to the bamboo, which leads that glued laminated bamboo wood must use special screws. The research of special screws of glued laminated bamboo wood is very important to furniture's design, production and hardware's development [1]. According to the survey of enterprise production, it was found that the special screws of glued laminated bamboo wood often have insufficient joint strength. Some screws damaged the fibers of the base materials when they were screwed in, resulting in slipping phenomenon and poor joint strength [2]. In the survey of partial rework of the products, it was found that the joint parts between the hardware with thread and the base material were loosened, and the splitting phenomenon was even found in the joint parts along with the texture. In view of the above situation, this paper carries out single factor pull-out test of assembly $\&$ disassembly number for joint strength of special screws of glued laminated bamboo wood, to find the influence law of assembly \& disassembly number for joint strength of screws.

\section{TEST MATERIALS AND EQUIPMENT}

\section{A. Test Materials}

(1) The test base material is glued laminated bamboo wood, the assembling method is flat, with an arrange density of $0.7 \mathrm{~g} / \mathrm{cm} 3$, as shown in Figure 1 . The length of base material is $60 \mathrm{~mm}$, the width is $60 \mathrm{~mm}$, the thickness is $30 \mathrm{~mm}$ and the hole depth is $25 \mathrm{~mm}$. The diameter of the guide hole is $8.6 \mathrm{~mm}$, the corresponding screw tooth depth is $0.7 \mathrm{~mm}$ and the corresponding depth ration is 0.7 .

Figure 1 Schematic diagram of assembling method of glued laminated bamboo wood

(2) Guide hole is made in the center point of specimen of glued laminated bamboo wood, with depth of $25 \mathrm{~mm}$, as shown in Figure 2. 


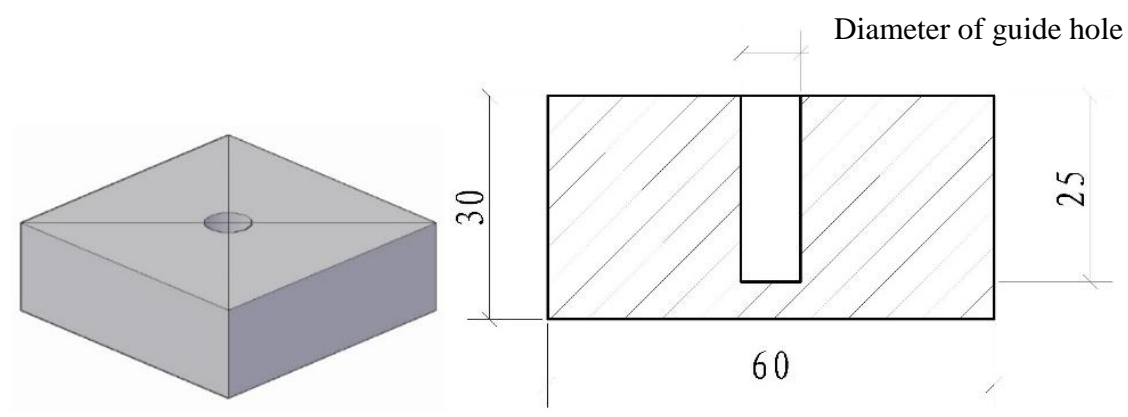

Figure 2 Schematic diagram of specimen size and guide hole

(3) In order to adapt to the fixture of pull-out test, we choose the screw head with a flat head and a diameter of $10 \mathrm{~mm}$, and choose the rod screw with length of $15 \mathrm{~mm}$ and diameter of $8 \mathrm{~mm}$. The thread parameters are as follows: tooth angle is $40^{\circ} \mathrm{C}$, tooth height is $1 \mathrm{~mm}$ and tooth distance is $2 \mathrm{~mm}$, as shown in Figure 3.
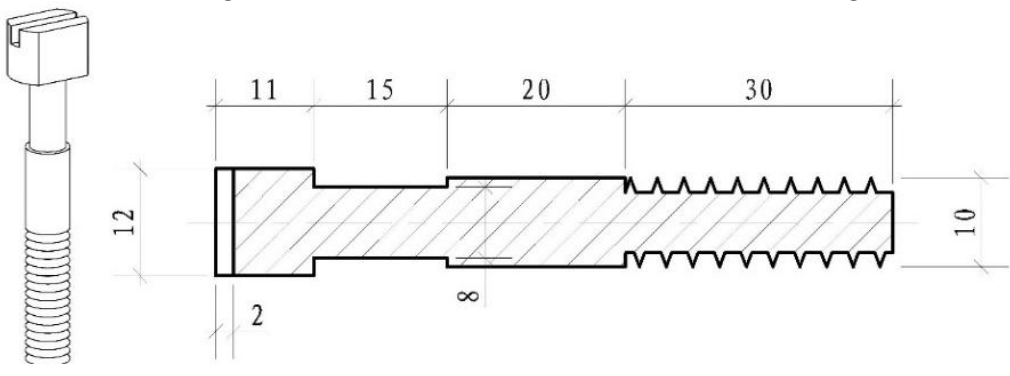

Figure 3 Schematic diagram of screw shape and size

\section{TEST EQUIPMENT}

Test equipment includes: single-sided woodworking planer, thin woodworking band saw, precision monolithic

\section{TEST METHODS}

\section{A. Test Design}

The loading speed of pull-out test is $12 \mathrm{~mm} / \mathrm{min}$, the load accuracy is $0.01 \mathrm{~N}$ and the displacement accuracy is $0.01 \mathrm{~mm}$. The operation process of pull-out test is as follows: place the specimen with screw on the fixture and by handle to adjust the position of the upper and lower fixture, so that they are close to the specimen but not be stressed. After the adjustment is completed, press the button to start the loading procedure, then tensile load is started and the load is automatically recorded by the computer. When the tensile load is $50 \mathrm{~N}$, the computer will automatically start recording the displacement value. When the screw is pulled out of the base material or the tensile load is sharply reduced to a very small value, the mechanical test machine shall automatically stop loading, take out the pulled screws and the base material, and the test ends. The maximum value of the load recorded automatically by the computer will be the result of this pull-out test intensity. Repeat the above procedure, repeat test 6 times for each test condition, and take the average of 6 times as the final test result. The test is divided into 6 groups: 0 time of assembly \& disassembly, 5 times of assembly \& disassembly, 10 times of assembly \& disassembly, 15 times of assembly \& disassembly, 20 times saw, hole-punching machine, universal mechanical test machine and vernier caliper, etc.

of assembly \& disassembly, 25 times of assembly \& disassembly and 30 times of assembly \& disassembly, the specimen number of each group is 6 and the test result is the mean value of 6 specimens.

\section{B. Observation Method of Damage Form of Specimen of Pull-out Test}

The observation method of damage degree of base material fiber is as follows: the specimen is longitudinally split along the guide hole in the axial direction and in the diameter position with a circular saw, and the damage degree of the inner wall of the guide hole and the surface fiber of the base material is observed with jade eyes. The main basis for judging the damage degree of base material fiber is the elevation of the surface of base material around the guide hole.

\section{V.TEST RESULTS AND ANALYSIS}

\section{A. Observation and Analysis of Damage Form of Specimen of Pull-out Test}

The damage form of base material of pull-out test under different number of assembly $\&$ disassembly is as shown in Table 1. 
TABLE 1 INFLUENCE OF NUMBER OF ASSEMBLY \& DISASSEMBLY ON DAMAGE DEGREE OF BASE MATERIAL

\begin{tabular}{|c|c|c|c|c|c|c|}
\hline Number & 0 & 5 & 10 & 15 & 20 & 25 \\
\hline Damage & & & & & & \\
\hline $\begin{array}{l}\text { form of } \\
\text { guide }\end{array}$ & & & & & & \\
\hline hole & & & & & & \\
\hline wall of & & & & & & \\
\hline $\begin{array}{l}\text { base } \\
\text { material }\end{array}$ & & & & & & \\
\hline
\end{tabular}

According to Table 1, it can be seen from the appearance of base material damage that the influence of number of assembly \& disassembly is not obvious, the degree of fiber breakage is not very different, and the degree of fiber shedding is basically the same as the fiber elevation. However, in the joint position between screw tooth and fiber the base material that is not assembled \& disassembled is more regular, and the groove marks of screw tooth embedded in base material are clearly visible. With the increase of the number of assembly \& disassembly, the joint marks between screw tooth and base material fiber are more and more blurred. This is because after a number of assembly \& disassembly, the screw tooth repeatedly rubs the base material, and more fiber fine particles are extruded and worn out, the more the number of assembly \& disassembly, the more obvious the situation. This indicates that the number of assembly \& disassembly is more obvious to the damage of base material fiber of screw joint. In the process of assembly \& disassembly, the wear of fibers reduces the contact intimacy between screw tooth and base material fiber, also reduces the thickness of the fiber embedded in the screw tooth, thus reducing the shear strength between the screw tooth and the fiber.

\section{B. Results and Analysis of Pull-out Strength}

The joint strength corresponded by different number of assembly \& disassembly is as shown in Table 2 and Figure 4.

$$
\text { TABLE } 2 \text { PULL-OUT TEST STRENGTH OF SPECIMEN }
$$

\begin{tabular}{cccccc}
\hline $\begin{array}{c}\text { Number of assembly \& } \\
\text { disassembly (Time) }\end{array}$ & 0 & 5 & 10 & 15 & 20 \\
\hline Maximum pullout load (N) & 9552.09 & 9261.79 & 8963.54 & 8437.52 & 8103.13 \\
\hline
\end{tabular}

According to Table 2 and Figure 4, it can be seen that the number of assembly \& disassembly has very obvious influence on pull-out strength of screw joint. There is a negative linear correlation between the number of assembly
$\&$ disassembly and pull-out load, which can be expressed by $y=-65.76 x+9550.10$, the correlation coefficient is $R=-0.98$ and the correlation is close.

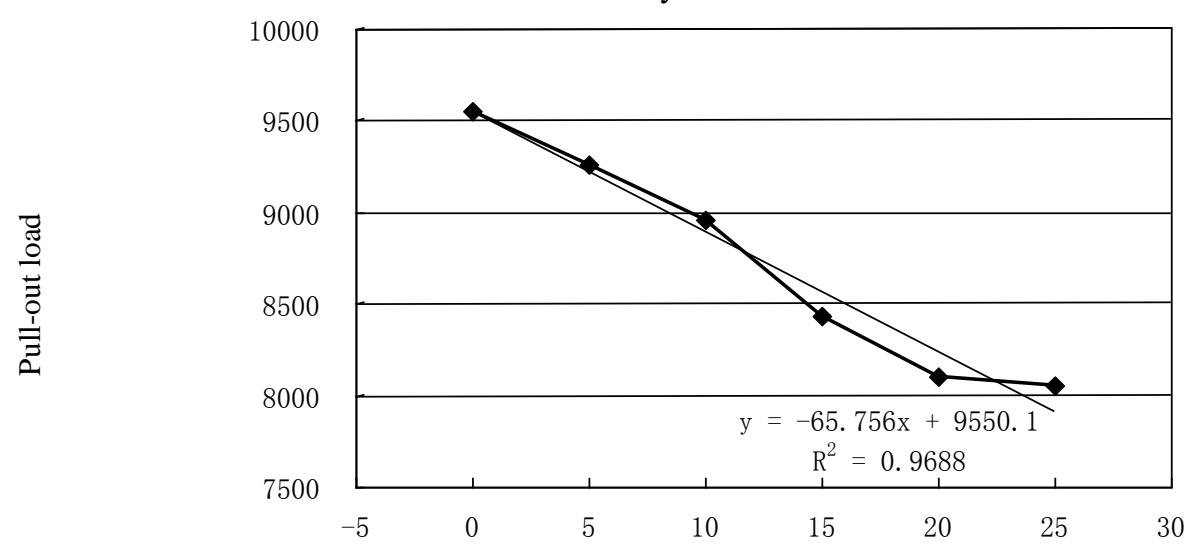

Number of assembly \& disassembly (Time)

Figure 4 Pull-out test strength of specimen

\section{CONCLUSION}

Under different number of assembly \& disassembly, the pull-out test results of screw joint are as follows:

The clearness of groove marks of screw tooth embedded in base material fiber gradually becomes blurred with the increase of number of assembly \& disassembly. The wear degree of screw tooth to base material fiber gradually becomes serious with the increase of number of assembly \& disassembly. The number of assembly \& disassembly has a significant effect on the mechanical strength of screw joint. 
Pull-out load decreases gradually with the increase of number of assembly \& disassembly, the two have a positive linear correlation, which can be expressed by $\mathrm{y}=-65.76 \mathrm{x}+$ 9550.10, the correlation coefficient is $\mathrm{R}=-0.98$ and the correlation is very close.

\section{REFERENCES}

[1] Liu Zhongchuan. Production Technology of Wood Products [M]. China Forestry Publishing House. 1991. (In Chinese)

[2] Wang Fenghu. Modern Furniture Design and Manufacture [M] Heilongjiang Science and Technology Press, 1994. (In Chinese) 